\title{
Role of Ultra Sonography in Abdominal Injuries
}

\author{
Ramgopal', Jamil Shaik $^{2}$ \\ ${ }^{1}$ Professor, Department of Radio diagnosis, Chalimeda Anandarao of medical college Karimnagar, Telangana, ${ }^{2}$ Assistant Professor, Department of Radio diagnosis, Icare
} inistitute of medical sciences Haldia, West Bengal.

\section{Abstract}

Background: Ultrasonography is a cheap, Readily avaialable, safe and non invasive investigation used in the evalution of patients with abdominal injuries No radiation effects are seen in ultrasonography Along with ultrasonography, CT scan and MRI is also used in diagnosing different abdorminal lesions. Aim of the study: Aim of our study was to evaluate diagnostic value of ultrasonography in the patients with abdominal injuries. Subjects and Methods: 120 patients were included in this study. Out of these 120 patients 95 patients were admitted with blunt abdominal trauma and 25 patients were admitted with penetrating abdominal injuries.Ultrasonography results in each patients is classified as true positive, false positive and false negative by comparing with findings at either diagnostic peritoneal lavage or surgery (1). Results: Out of 120 abdominal injury patients 95 were with blunt trauma and 25 patients were admitted with penentrating abdominal injuries. By scanning to detect free fluid, true positive were $102(85 \%)$ and false positive were $8(6.6 \%)$ false negative $6(5.2 \%)$ true negative are $9(7.5 \%)$. Conclusion: ultrasonography has a high diagnostic value in the screening of patients with blunt abdominal trauma and penetrating type injuries. In devoloping countries and in rural part of india emergency diagnosic facilities especially radiological investigations like ultrasonography and CT scan are lacking. So governement has to take initiations in arranging these type of diagnostic facilities to prevent the morbidity and mortality due to abdominal injuries.

Keywords: ultrasonography, abdominal injuries, diagnosis, haemo paritoneum.

Corresponding Author: Dr. Jamil Shaik, Assistant Professor, Department of Radio diagnosis, Icare inistitute of medical sciences Haldia, West Bengal.

Received: April 2018

Accepted: May 2018

\section{Introduction}

Ultrasonography is a technique using echoes of ultrasound pulses to delineate objects or areas of different density in the body. ${ }^{[2]}$

In Blunt abdominal injries, most of them are caused by road traffic accidents, fall from heiht and hitting with any objects, the organs injured are liver, spleen, kidney, omentum, intistines, kidneys and urinary bladder.

In penetrating injuries the organs injured are liver, spleen, pancreas, abdominal aorta, stomach, intestines kidneis, and urinary bladder

The injuries may be contusions, mild lacarated injuries and sometimes associated with large lacarated injury with massive bleeding into peritioneal cavity and sometimes with haematoma formation. ${ }^{[3]}$

Abdominal raidography has historically been the first imaging examination performed in the emergency department in evaluating abdominal pain. Interpretation of these radiographs may present a formibidable challenge to the radiologist. ${ }^{[4]}$

Unlike in the devoloping countries, in the devoloped countries there is a prepondarence of available diagnostics tools. Most of the authors would regard CT scan, laroscopy, diagnostic peritoneal lavage and abdominal ultrasonograpy as key tools in the evaluation of patients with blunt abdominal trauma. ${ }^{[5,6]}$

\section{Subjects and Methods}

We have admitted 120 abdominal injury patients in emergency surgey department out of these 120,95 are due to blunt injury abdomen 25 are due to peventrating injury.

\begin{tabular}{|l|l|l|l|}
\hline \multicolumn{4}{|c|}{ Table 1: of abdominal injuries in different age groups. } \\
\hline S.no & Age group & $\begin{array}{l}\text { Blunt injury } \\
\text { abdominal }\end{array}$ & Penetrating type \\
\hline 1 & $20-29 y r s$ & $15(15.7 \%)$ & $7(28 \%)$ \\
\hline 2 & $30-39 y r s$ & $31(32.6 \%)$ & $8(32 \%)$ \\
\hline 3 & $40-49 y r s$ & $23(24.21 \%)$ & $4(16 \%)$ \\
\hline 4 & $50-59 y r s$ & $15(15.78 \%)$ & $3(12 \%)$ \\
\hline 5 & Above 60yrs & $11(11.51 \%)$ & $3(12 \%)$ \\
\hline
\end{tabular}

\section{Results}

The most common age group in both types of abdominal injuries, blunt injury and penetrating injury are 30 to 50 years. That is most active age group. The organs injured are liver, kidney, bowel, spleen, and omentum. Most common cause for injuries are motor vehicle accidents; fall from height because the people who are in active age group moves one place to other or they travel by cars, motorcycles etc. 


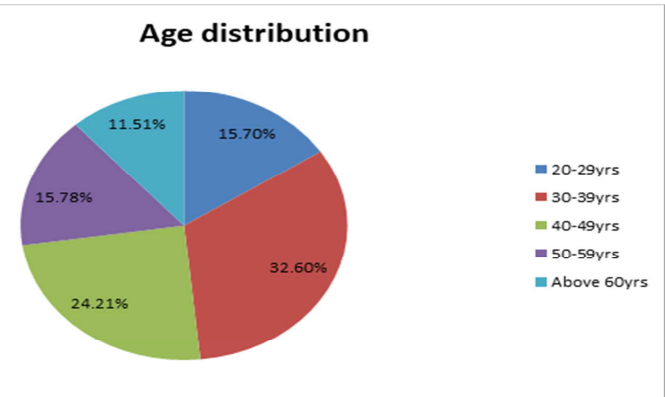

Figure 1: Age Distribution.

Table 2: Different organ injuries
\begin{tabular}{|l|l|l|}
\hline S.No & Organ Injured & No. of patients injured \\
\hline 1 & Liver & $30(30.84 \%)$ \\
\hline 2 & Spleen & $14(14.84 \%)$ \\
\hline 3 & Bowel & $13(13.68 \%)$ \\
\hline 4 & Omentum & $13(13.68 \%)$ \\
\hline 5 & Kidney & $9(9.47 \%)$ \\
\hline 6 & Others & $8(8.42 \%)$ \\
\hline
\end{tabular}

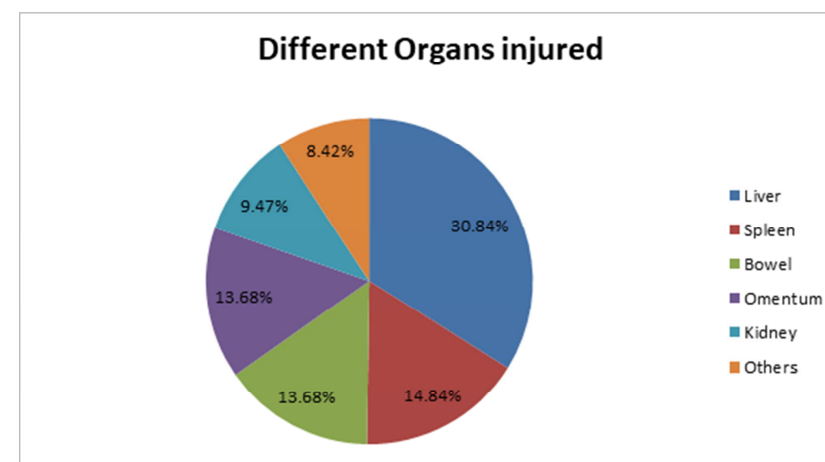

Figure 2: Organs Injured.

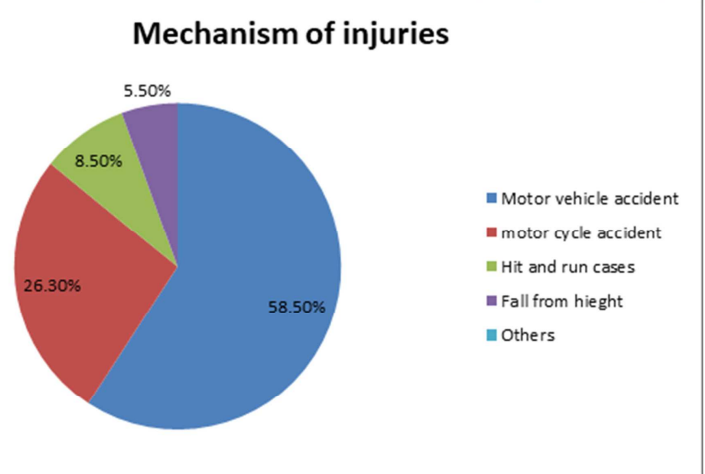

Figure 3: Motor vehicle accident cars and motorcycles etc.

\section{Discussion}

Ultrasonography is very much useful investigation in abdominal injuries especially blunt injuries. It is decrease morbidity and mortality in conditions like deep lacerated liver injury, splenic rupture, hemoperitoneum.

All patients had routine resuscitation and treatment in the emergency treatment includes maintenance of air way with control of cervical spine, ensuring adequate breathing and maintained of circulation with IV fluids including blood transfusion in severe hemorrhage

Ultrasonography is ready available, accessible and it is a non-invasive procedure with high patient's acceptability. However the ultrasound results are operator dependent. This may alter the reliability of ultrasound in the abdominal trauma. In our study the ultra sound scan were carried out mostly by qualified radiologists only.

In our study the sensitivity of ultrasound scan for detecting intra-abdominal injury when scanning for hemoperitoneum is very good at $95 \%$ and the study conducted by yoshii et al. ${ }^{[7]}$

Shows almost similar results $96.5 \%$. In the retrospective study carried out on 2693 patients by Brown et al. ${ }^{[8]}$

The sensitivity was reported at $85 \%$ which is having is lower than $95 \%$ found in this study. In our study 73 Patients $(76.84 \%)$ had intra-abdominal fluid 69 patients $(72.12 \%)$ has correctly identified remaining 4 patients $(4.21 \%)$ had positive DPL diagnostic paritoned lavage).

This may be probably due to volume of collection was smallar than could have been detected sonographically challenges encountered in the course of US imaging in this study included the limitation of sonographic window when patients had skin abrasion and dressing on aturor abdominal wall there was also a limited seen for manunring the injured patients due to pain.

When ultrasonogram was done for organ damage the sensitivity was $69.95 \%$ In the surgery organ injury is noted in 85 patients $86.78 \%$ but sonographically it is 70 patients $69.95 \%$ hemoperitoneum was diagnosed acurately. In injury to spleen 3 cases were missed sonographically. In bowel injuries 4 cases were not detected.

False negative and false positive cases which were noted in our study were nearer to the similar results which were shown by other authors. ${ }^{[9,10]}$
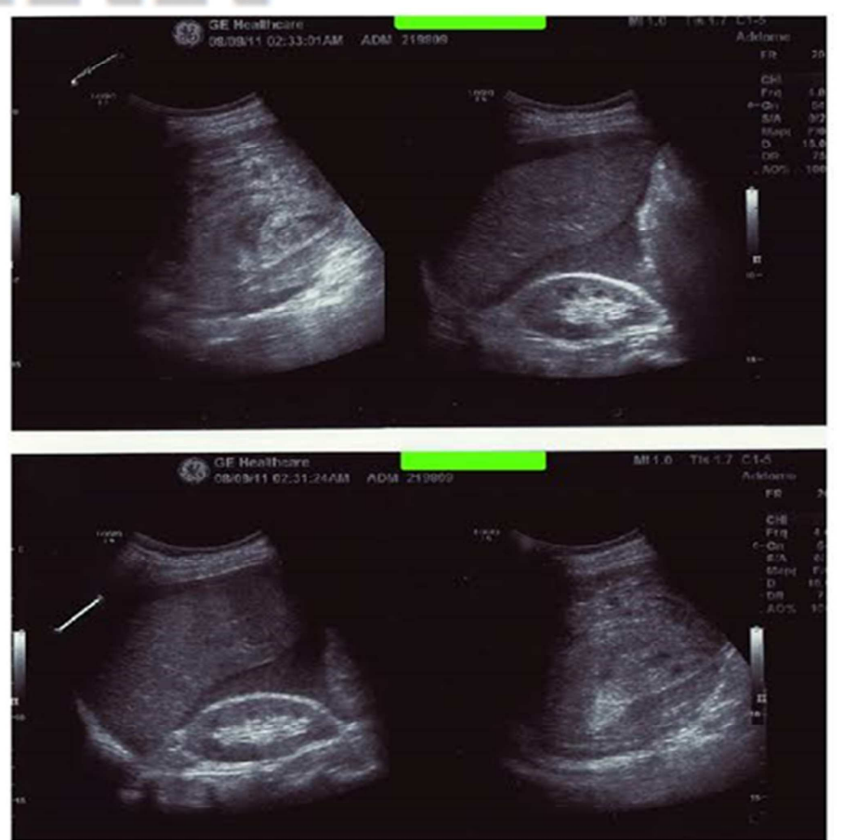

Figure 4: Abdominal Ultrasonography shoing the spleen rupture with hemoperitoneum. 
The pattern of visceral injury in our study shows that 85 patients had organ $(86.25 \%)$ injury 26 patients has multiple organ injury. In multiple organ injury liver, spleen were injured commonly.

\section{Conclusion}

Ultrasonography is very much useful in diagnosis of abdominal injuries scanning for presence of free intra portioned fluid yeilded better results than scanning for visceral parenchymal injury. In rural part of India, still diagnostic facilities like ultrasonography and CT scan has to be improved to reduce the morbidly and mortality duc to abdominal injuries.

\section{References}

1. Drown MA, Casola or, sislin CB, patel NY hoyt DB blunt abdominal trauma screening US in 2,693 patients radiology 2001,218-352-8.
2. Hudson Ap, Susan BP. Emergency med clinics of north amer 1997; 15-825-846.

3. Spigelman AD. Acute abdominal conditions. In Henry MH; Thompson JN edutors clinical surgery 2 nd edi china elsevier sanders $2005 ; 365-$ 366.

4. Nirapathpong porn.s; Osatevanichavg K. Udompanich. Pneumo peritoneum detected by ultrasound radiology 1984. 150:831

5. Stengle D. Bauwens K. Pozysolt F. rasemacher G. mulyes. Emergency ultrasound for blunt abdominal injuries. Metanalysis update 2003.

6. Stengle D. Bauwens K. Pozysolt F. rasemacher G. mulyes. Emergency ultrasound for blunt abdominal injuries. Metanalysis update 2003.

7. Yoshii H. salo $M$, yamamotoS, motegi $M$ et al. usefulness and limitations of ultrasonography in the initial evaluation of blunt abdominal trauma. I. trauma, 1998;45:45-50.

8. Brown MA, casola G, Sirlin CB patel NY blunt abdominal trauma screening US in 2693 patients Rasiology 2001, 2018, 352-8. The sensitivity was reposted at $85 \%$ which is lower than $95 \%$ final in this study.

9. Richands JR, Knopf NA, wangl, MC Galan JP sonographic assesment blunt abdominal trauma, 2Years prospective study J.Clin ultrasound 2001,30.59-67.

10. Richands JR, Knopf NA, wangl, MC Galan JP sonographic assesment blunt abdominal trauma, 2Years prospective study J.Clin ultrasound 2001,30.59-67.

Copyright: (C) the author(s), publisher. Asian Journal of Medical Radiological Research is an Official Publication of "Society for Health Care \& Research Development". It is an open-access article distributed under the terms of the Creative Commons Attribution Non-Commercial License, which permits unrestricted non-commercial use, distribution, and reproduction in any medium, provided the original work is properly cited.

How to cite this article: Ramgopal, Shaik J. Role of Ultra Sonography in Abdominal Injuries. Asian J. Med. Radiol. Res. 2018;6(2):36-38.

DOI: dx.doi.org/10.21276/ajmrr.2018.6.1.10

Source of Support: Nil, Conflict of Interest: None declared. 